\title{
Effect of physicochemical surface treatments on the bond strength and adhesion of porcelain denture teeth to heat-polymerized acrylic resin denture base material
}

\author{
Sipahi, Cumhur ; Özcan, Mutlu ; Piskin, Bülent
}

\begin{abstract}
The aim of this study was to compare the effect of physicochemical surface treatments on the adhesive bond strength of porcelain denture teeth (PDT) to acrylic resin denture base material (PMMA). Totally, 100 PDT specimens, 50 with retentive palatal pins $(+\mathrm{P})$ and 50 without pins $(-\mathrm{P})$, were selected and assigned to 10 experimental groups $(n=10)$. Control groups $C O N-P$ and $C O N+P$, did not receive any treatment. Groups $S B+$ $\mathrm{P}$ and SB-P were sandblasted, groups $\mathrm{SB} / \mathrm{AE}+\mathrm{P}$ and $\mathrm{SB} / \mathrm{AE}-\mathrm{P}$ were sandblasted and acid-etched, groups TSC $+\mathrm{P}$ and TSC-P were tribochemically silica-coated, and groups FB $+\mathrm{P}$ and FB-P were covered with fibers. Cylindrical PMMA rods were polymerized onto treated palatal PDT surfaces. Force $(\mathrm{N})$ was applied on palatal incisal edges of PDT specimens until debonding of PMMA. Obtained data were statistically analyzed with Kruskal-Wallis and Bonferroni corrected Mann Whitney U tests. The significance level was set at $(\mathrm{p}<.05)$. Mean force values of test groups ranged in descending order as follows: $\mathrm{TSC}+\mathrm{P}(132.5 \mathrm{~N} \pm 26.5), \mathrm{SB}+\mathrm{P}(113.5 \mathrm{~N} \pm 47.5), \mathrm{SB} / \mathrm{AE}+\mathrm{P}(112.2 \mathrm{~N}$ $\pm 26.1), \mathrm{CON}+\mathrm{P}(103.1 \mathrm{~N} \pm 39.6)$, TSC-P (90.6 N \pm 22.2$), \mathrm{FB}+\mathrm{P}(77.7 \mathrm{~N} \pm 18.3), \mathrm{SB} / \mathrm{AE}-\mathrm{P}(47.6 \mathrm{~N} \pm 10.5), \mathrm{SB}-\mathrm{P}(18.1 \mathrm{~N}$ $\pm 4.0)$, $C O N-P(4.6 \mathrm{~N} \pm 5.4)$, and $\mathrm{FB}-\mathrm{P}(0.0 \mathrm{~N} \pm 0.0)$. No significant difference was found between groups with pins $(+\mathrm{P})$ except group $\mathrm{FB}+\mathrm{P}$ which displayed lower values than $\mathrm{CON}+\mathrm{P}(\mathrm{p}<.024)$, and TSC $+\mathrm{P}(\mathrm{p}<045)$. Groups $(+\mathrm{P})$ showed significantly higher bond strength values than groups $(-\mathrm{P})$ except for group TSC-P $(\mathrm{p}<.09$ and $\mathrm{p}<1)$. In groups without pins $(\mathrm{P}-)$, differences between groups were significant and ranged as follows: TSC-P $>\mathrm{SB} / \mathrm{AE}-\mathrm{P}$ $(\mathrm{p}<.0094), \mathrm{SB} / \mathrm{AE}-\mathrm{P}>\mathrm{SB}-\mathrm{P}(\mathrm{p}<.007)$, and SB-P > CON-P $(\mathrm{p}<.0013)$. Groups CON-P and FB-P did not show differences $(\mathrm{p} \leq 1)$. Groups $(+\mathrm{P})$ displayed higher bond strength values than groups $(-\mathrm{P})$. SB-P, SB/AE-P, and TSC-P increased the adhesive bond between PDT and PMMA, respectively. Fiber coating negatively affected the bond.
\end{abstract}

DOI: https://doi.org/10.1080/00218464.2012.648874

Posted at the Zurich Open Repository and Archive, University of Zurich

ZORA URL: https://doi.org/10.5167/uzh-75642

Journal Article

Accepted Version

Originally published at:

Sipahi, Cumhur; Özcan, Mutlu; Piskin, Bülent (2012). Effect of physicochemical surface treatments on the bond strength and adhesion of porcelain denture teeth to heat-polymerized acrylic resin denture base material. The Journal of Adhesion, 88(2):200-212.

DOI: https://doi.org/10.1080/00218464.2012.648874 
Effect of physicochemical surface treatments on the bond strength and adhesion of porcelain denture teeth to heat-polymerized acrylic resin denture base material

(Adhesive bond between porcelain denture teeth and acrylic resin)

Cumhur Sipahi, DDS, $\mathrm{PhD}^{1}$, Bülent Piskin, DDS, PhD. ${ }^{2}$, Mutlu Özcan ${ }^{3}$, DDS, Dr. Med. Dent, PhD

${ }^{1}$ Associate Professor, Head of Department of Prosthodontics, Academic Center for Dental Sciences, Gülhane Military Medical Academy, Ankara, Turkey.

${ }^{2}$ Assistant Professor, Department of Prosthodontics, Academic Center for Dental Sciences, Gülhane Military Medical Academy, Ankara, Turkey.

${ }^{3}$ Professor, Head of Dental Materials Unit, Center for Dental and Oral Medicine, Clinic for Fixed and Removable Prosthodontics and Dental Materials Science, Zurich, Switzerland.

Corresponding Author: Dr. Cumhur SIPAHI

E-Mail Address: cumhursipahi@yahoo.com,

Phone:+903123046054,

Fax: +903123046020

Mailing Address; Gulhane Military Medical Academy, Center for Dental Sciences, Department of Prosthodontics, Etlik, 06018, Ankara, TURKEY. 


\section{ABSTRACT}

The aim of this study was to compare the effect of physicochemical surface treatments on the adhesive bond strength of porcelain denture teeth (PDT) to acrylic resin denture base material (PMMA). In total, 100 PDT specimens; 50 with retentive palatal pins (+P), 50 without pins (-P) were selected and assigned to 10 experimental groups $(n=10)$. Control groups; $\mathrm{CON}-\mathrm{P}$ and $\mathrm{CON}+\mathrm{P}$, did not receive any treatment. Groups $\mathrm{SB}+\mathrm{P}$ and $\mathrm{SB}-\mathrm{P}$ were sandblasted, groups $\mathrm{SB} / \mathrm{AE}+\mathrm{P}$ and $\mathrm{SB} / \mathrm{AE}-\mathrm{P}$ were sandblasted and acid etched, groups TSC $+\mathrm{P}$ and TSC-P were tribochemically silica coated, and groups $\mathrm{FB}+\mathrm{P}$ and $\mathrm{FB}-\mathrm{P}$ were covered with fibers. Cylindrical PMMA rods were polymerized onto treated palatal PDT surfaces. Force (N) was applied on palatal incisal edges of PDT specimens until debonding of PMMA. Obtained data were statistically analyzed with Kruskal-Wallis and Bonferroni corrected Mann Whitney $U$ tests. The significance level was set at $(p<.05)^{*}$. Mean force values of test groups ranged in descending order as follows; TSC+P (132.5 $\mathrm{N} \pm 26.5)$, $S B+P(113.5 N \pm 47.5), S B / A E+P(112.2 N \pm 26.1), C O N+P(103.1 N \pm 39.6), T S C-P(90.6 N$

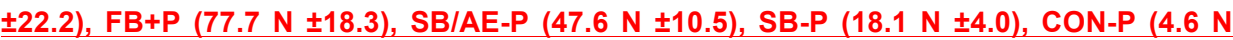
$\pm 5.4)$, and FB-P $(0.0 \mathrm{~N} \pm 0.0)$. No significant difference was found between groups with pins $(+P)$ except for group FB+P which displayed lower values than CON+P $(p<.024)$, and TSC+P $(p<045)$. Groups $(+P)$ showed significantly higher bond strength values than group (-P) except for group TSC-P $(p<.09$, and $p<1)$. In groups without pins ( - -), differences between groups were significant and ranged as follows; TSC-P > SB/AE-P $(p<.0094)$, SB/AE-P > SB-P $(p<.007)$, SB-P > CON-P $(p<.0013)$. Groups CON-P and FB-P did not show significant difference $(p \leq 1)$. Groups $(+P)$ displayed higher bond strength values than groups (-P). SB-P, SB/AE-P and TSC-P jncreased the adhesive bond between PDT and PMMA, respectively. Fiber coating negatively affected the bond.

KEYWORDS: Porcelain denture teeth, PMMA, Adhesive bond strength, Tribochemical silica coating, Sandblasting.
Mutlu Özcan 25.10.11 20:03

Gelöscht: in descending order Mutlu Özcan 25.10.11 20:04

Gelöscht: s

Gelöscht: respectively 


\section{INTRODUCTION}

\section{Especially in developed countries, since the the number of elderly people is growing,} as a consequence of tooth loss due to root caries, periodontal problems the number of denture wearers is increasing [1-3]. Polymethyl methacrylate (PMMA) resin is still the most frequently used material in denture base fabrication [4]. Either porcelain denture teeth (PDT) or acrylic resin denture teeth can be employed in the fabrication of complete or partial dentures. However, PDT are generally considered to be more esthetic than acrylic teeth and they are also much more resistant to occlusal wear which is crucial for the maintenance of the determined occlusal vertical dimension. PDT also have the advantage of being the only type of denture teeth that allow the denture to be rebased $[5,6]$. The growing trend of denture wearing population toward highly esthetic removable dentures leads to the increasing use of PDT namely in the anterior edentulous region.

The manufacture of PDT is based on the use of high-fusing dental ceramics [2]. PDT are typically joined to heat-polymerized acrylic resin denture bases by mechanical retentive features such as metal pins or diatoric undercuts. Because the retention is primarily mechanical, one of the most common areas of failure in a denture fabricated with PDT is the bond between the PDT and the denture base [7]. Besides, a low vertical interocclusal space or a lack of space inherent from the denture's metal framework may often preclude the use of retentive diatorics or pins, thus worsening the limited mechanical bond of PDT to acrylic resin denture base. In such cases, providing the retention of PDT to PMMA resin denture base may be a great challenge for the clinician.

Several surface treatment methods such as etching [8], silane coating with use of bonding agent $[9,10]$ or ceramic primer application [10] have been used to enhance the bond of PDT to PMMA. The role of surface treatment in the mechanism of adhesion revealed that surface topography alone did not account for all differences found in the comparison of such surface treatment [11].
Mutlu Özcan 25.10.11 20:05

Gelöscht: Namely in

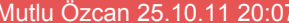

Gelöscht: as the number of elderly people is growing

Mutlu Özcan 25.10.11 20:07

Gelöscht: ,

Mutlu Özcan 25.10.11 20:07

Gelöscht: and $p$ 
Recent advances in surface conditioning methods provided improved bond strength of the resin to alloys or ceramic materials [12]. The CoJet ${ }^{\circledR}$ System (3M, ESPE, Seefeld, Germany), which is one of the tribochemical silica coating methods, provides ultra-fine mechanical retention by air particle abrasion, as well as a chemicophysical bonding between the resin composite and alloy/ceramic surfaces when used with a silane coupling agent [1316]. This technique involves the blasting of alloy or ceramic surface with $30 \mu \mathrm{m}$ grain size $\mathrm{Al}_{2} \mathrm{O}_{3}$ particles modified with silisic acid $\left(\mathrm{CoJet}^{\circledR}-\mathrm{Sand}\right)$, with an intraoral airborne particle abrasion unit. As a result, the silica particles are embedded on the blasted surface rendering the substrate chemically more reactive to resin via the silane.

Despite numerous studies reporting various physical and chemical surface treatment methods for the improvement of the bond strength between PDT and PMMA, the efficacy of these methods were not yet compared in any study. The aim of the present in vitro study was to compare the effect of various physical and chemical surface treatment methods on the bond strength of porcelain denture teeth to heat-polymerized acrylic resin denture base material.

\section{MATERIALS AND METHODS}

Identification of experimental groups

One hundred left central incisor PDT specimens (Ivoclar Vivadent, Vivaperl PE, Schaan, Liechtenstein) with standard dimensions (120/1A, A15) were selected and the retentive palatal pins of 50 specimens were eliminated by cutting with a rotary instrument. Fifty PDT specimens with retentive pins (+P) and 50 PDT specimens without retentive pins (-P) were assigned to 10 experimental groups $(n=10)$ according to the surface treatment procedure applied on palatal surfaces (Table 1). Identification of experimental groups was as follows:

Group CON+P; the control group with retentive pins, and Group CON-P; the other control group without retentive pins consisted of untreated PDT specimens. Group SB+P consisted of sandblasted specimens with retentive pins and Group SB-P consisted of sandblasted specimens without retentive pins. Group SB/AE+P consisted of sandblasted and acid etched specimens with retentive pins and Group SB/AE-P consisted of sanblasted and 
acid etched specimens without retentive pins. Group TSC+P consisted of tribochemically silica coated specimens with retentive pins and Group TSC-P consisted of tribochemically silica coated specimens without retentive pins. Finally, Group FB+P consisted of fiber covered specimens with retentive pins and Group FB-P consisted of fiber covered specimens without retentive pins.

\section{Specimen preparation}

The $2 / 3$ of the palatal surface of a selected PDT specimen was covered with modeling wax (Cavex). The incisal palatal third was left uncovered. The modeled wax was lengthened such as to form a $3 \mathrm{~cm}$ high cylindrical configuration perpendicular to the palatal plane of PDT.

An open-ended cylindrical metal ring $(4 \mathrm{~cm}$ in heigth and $3 \mathrm{~cm}$ in diameter) was filled with freshly poured heavy body silicon impression material (Exaplast, Detax, Ettlingen, Germany). The waxed PDT specimen was introduced into the metal ring such as the labial PDT surface remained out of the impression material, positioning $2 \mathrm{~mm}$ below the level of the ring's aperture.

After setting of heavy body silicon impression material, the waxed PDT specimen was retrieved from the metal ring. A freshly poured light body silicon impression material (Exasoft, Detax, Ettlingen, Germany) was injected into the cavity obtained in the heavy body silicon bulk. The retrieved PDT specimen was reintroduced into the cavity filled with light body silicon impression, and after setting, it was once again retrieved from the metal ring and a high precision negative silicon index of a waxed PDT specimen was obtained.

The palatal surface of each PDT specimen was one by one repositioned onto the obtained silicon index and fastened with use of sticky wax (Dentsply Inc, York, Pa). Fused modeling wax was flowed from the opposite aperture of the metal ring such as to totally fill the $3 \mathrm{~cm}$ long cavity obtained into the silicon index by fully covering the palatal surface of fastened PDT specimens. After cooling of wax patterns into a bowl full of water at $4^{\circ} \mathrm{C}$ temperature, the PDT specimens were retrieved from the silicon index, and wax patterns with standard length $(3 \mathrm{~cm})$ and surface area were obtained onto the palatal surface of each PDT specimen. 
One hundred waxed PDT specimens were randomly assigned to 10 experimental groups $(n=10)$ and flasked; one group to one flask, such as to obtain 10 metal flasks in total. The cylindrical wax portions of PDT specimens were vertically positioned into freshly poured Type II dental stone (Moldano, BAyer, Germany), perpendicular to the horizontal plane of flask bases, such as the PDT bodies and labial surfaces remained into the upper flask pieces. The palatal surfaces of PDT specimens were located at the junction level of upper and lower flask pieces.

After the setting of flask stones, the flasks were heated for 15 minutes into boiling water to soften the wax portions of PDT specimens. After heating procedure, the flasks were opened, and softened wax was evacuated from the flasks by boiling water spray.

\section{Surface treatment procedures}

Specimens of Groups CON+P and CON-P were left untreated.

The palatal surfaces of PDT specimens of Groups SB+P and SB-P were subjected to sandblasting (Superstrahl, Degussa AG, D-6000, Frankfurt, Germany) using $50 \mu \mathrm{m}$ alumina particles. The sandblasting procedure was applied perpendicular to specimen surfaces from a distance of $10 \mathrm{~mm}$, for 1 minute, under 2.5 bar pressure.

The palatal surfaces of PDT specimens of Groups SB/AE+P and SB/AE-P were first subjected to sandblasting as described for SBL groups, and subjected to $30 \%$ concentrated hydrofluoric acid for 5 minutes.

The palatal surfaces of PDT specimens of Groups TCS+P and TCS-P were subjected to tribochemical silica coating procedure. The PDT surfaces were treated with $30-\mu \mathrm{m}$ silicondioxide particles (CoJet ${ }^{\mathrm{TM}}$ Sand, 3M ESPE AG, Dental Products, D-82229 Seefeld, Germany) using an air-borne particle abrasion device (CoJet System, 3M ESPE, Seefeld, Germany). Silica particles were applied perpendicular to specimen surfaces from a distance of $10 \mathrm{~mm}$, for 1 minute, under 2.5 bar pressure (Figure 1 ). 
Following silica coating procedure, a silane coupling agent (Clearfil Porcelain Bond Activator, Kuraray Medical Inc, Okayama, Japan) was applied on silica coated PDT surfaces with cotton pelets. The applied silane layers were allowed to dry for 5 minutes.

The palatal surfaces of PDT specimens of Groups FB+P and FB-P were sandblasted and silanized as described previously. Woven fibers (Stick Net, SN, Stick Tech Ltd, Turku, Finland) $(7 \mu \mathrm{m})$ were cut such as to fit onto palatal PDT surfaces. A bonding agent (Clearfil SE, Kuraray Medical Inc, Okayama, Japan) was applied on silanized PDT surfaces, prepared fiber sheets were placed with finger pressure onto bonded surfaces, and polymerization was performed with a light source (Heliolux DLX; Ivoclar Vivadent, Schaan, Liechtenstein) for 1 minute, at a distance of $1 \mathrm{~cm}$ from PDT specimen surfaces, with a polymerization light intensity of $500 \mathrm{~mW} / \mathrm{cm}^{2}$.

\section{Polymerization process of test specimens}

After the completion of surface treatment procedures, a heat-polymerized acrylic resin denture base material ( $Q C / 20$, Denstply Int Inc, Waybridge, Surrey, UK) was prepared according to the instructions of the manufacturer and the resin dough was placed into the stone cavities located into lower flask pieces. After two trial closures to remove excess resin, the flasks were pressed and heated for $30 \mathrm{~min}$ at $75^{\circ} \mathrm{C}$ and an additional $30 \mathrm{~min}$ at $100^{\circ} \mathrm{C}$. After the completion of polymerization, excessive acrylic resin tips were removed with tungsten carbide burs and totally 100 PDT specimens with acrylic resin cylinders on palatal surfaces were finished.

Totally 100 open-ended cylindrical plastic rings of $3.5 \mathrm{~cm}$ high and $2 \mathrm{~cm}$ in diameter were selected and filled with freshly poured autopolymerizing acrylic resin (Duralay; Reliance Dental Mfg, Worth, III) (Figure 2). The $1 / 2$ length $(1.5 \mathrm{~cm}$ ) of acrylic resin cylinder projections of PDT specimens were then embedded into the resin filled rings for obtaining a new cylindrical configuration to provide a well-fitting into the clamps of universal testing machine (Figure 3.a). 


\section{Loading procedure}

Cylindrical acrylic resin projections were clamped to the base of an universal testing machine (Instron 1195; Instron Corp, Canton, Mass) such as the uncovered 1/3 palatal incisal third surfaces of PDT specimens were positioned at a 45-degree angle to the horizontal plane (Figure 3.b). A rectangular stainless steel bar with a U-shaped tip (1-mm radius) was fixed vertically to apply shearing force to palatoincisal surfaces of the PDT specimens.

The tip of the loading bar was positioned to contact the center of the inclined palatoincisal surfaces at an angle of 135-degree angle. A constant compressive load was applied at a crosshead speed of $0.5 \mathrm{~mm} / \mathrm{min}$, until debonding occured.

The failure threshold was defined as the point at which the loading force reached the maximum value for debonding the attachment between the PDT and acrylic resin base. The applied load was automatically stopped at the first instance of specimen fracture. Force values at failure were measured and registered in Newtons $(\mathrm{N})$.

\section{Statistical analysis}

Obtained data were analyzed with a statistical software program (SPSS 15.0 for Windows, SPSS Inc, Chicago, III). The Kruskal-Wallis test was used for the comparisons between experimental groups. The Bonferroni corrected Mann Whitney $U$ test was used for dual comparisons. The significance level was set at $p<.05$.

\section{RESULTS}

Minimum, maximum, mean and standard deviation values were presented at Table 2. Boxplot of mean values and standard deviations were also depicted at Figure 4. Comparisons between experimental groups were shown at Table 3. The modes of failure of test specimens were given at Table 4. 
Highest force values were obtained in group TSC+P $(132.5 \mathrm{~N} \pm 26.5)$, followed respectively by $S B+P(113.5 \mathrm{~N} \pm 47.5), S B / A E+P(112.2 \mathrm{~N} \pm 26.1), C O N+P(103.1 \mathrm{~N} \pm 39.6)$, TSC-P (90.6 N \pm 22.2$), F B+P(77.7 \mathrm{~N} \pm 18.3)$, SB/AE-P (47.6 N \pm 10.5$)$, SB-P $(18.1 \mathrm{~N} \pm 4.0)$, CON-P (4.6 N \pm 5.4$)$, and FB-P $(0.0 \mathrm{~N} \pm 0.0)$. All groups including retentive pins (CON+P, $\mathrm{SB}+\mathrm{P}, \mathrm{SB} / \mathrm{AE}+\mathrm{P}$, and $\mathrm{TSC}+\mathrm{P}$ ) displayed higher bond strength values than groups without retentive pins, except for group TSC-P $(p>.09)$ which showed equivalent force values with $(+P)$ groups.

No significant difference was found between bond strength values of $(+P)$ groups $(C O N+P, S B+P, S B / A E+P$, and $T S C+P)$, except group $F B+P$ which displayed significantly decreased bond strength values $(p<.005)$.

In $(-P)$ groups, sandblasting (SB-P) $(p<.001)$, sandblasting and acid etching $(S B / A E-P)$ $(p<.005)$, and tribochemical silica coating $($ TSC-P) $(p<.005)$ improved the adhesive bond strength between PDT and PMMA. The bond increasing effect of TSC in groups without pins was significantly higher than SB $(p<.007)$ and SB/AE $(p<.009)$. Group SB-P showed significantly higher bond strength values compared to CON-P $(p<.001)$, indicating the positive effect of sandblasting on PDT surfaces. Likewise, group SB/AE-P showed significantly higher bond strength values than group SB-P $(p<.007)$, indicating the positive effect of acid etching on sandblasted PDT surfaces.

\section{DISCUSSION}

Prefabricated porcelain denture teeth (PDT) and polymethyl methacrylate (PMMA) are still widely used materials in current prosthetic restorative field. The use of these materials may frequently coincide in the fabrication of complete denture for patients with high esthetic demands. However, due to their different chemical and structural composition, PDT and PMMA cannot establish a chemical bond, thus forcing the dentist to seek mechanical retentive solutions such as the use of diatoric undercuts or retentive pins. Unfortunately, these Mutlu Özcan 25.10.11 20:11 mechanical retentive media are often far from providing a durable and sufficient attachment Gelöscht: between two materials. Moreover, in cases of unsufficient interocclusal space or in case of 
prominent metal framework use, the retentive pins or diatoric undercuts located on palatal surfaces of PDT are compulsorily eliminated to provide a suitable occlusion. In such cases, the mechanical means for retention of PDT on PMMA dentures becomes totally impossible and adhesive retention is needed. The present in vitro study aimed to evaluate the effect of various physical and chemical surface treatment methods on the mechanical and adhesive bond strength of PDT to a heat-polymerized acrylic resin denture base material.

Sandblasting (SB), sandblasting followed by acid etching (SB/AE), tribochemical silica coating (TSC) and fiber coating (FB) were the surface treatment methods applied on PDT specimens with and without retentive pins. Higher bond strength values were obtained in groups with retentive pins, with no significant differences.

Despite highest bond strengths values were always found in pin groups, no statistically significant difference was found between pin groups and group TSC-P. It can be stated that tribochemical silica coating (TSC) may be a suitable alternative to pin retention but cannot completely replace it. This is evident by the maximum value for CON+P (168.1 N) and for TSC+P (165.8 N). The TSC+P group, as well, displayed highest yet statistically insignificant bond strength values among groups with pins, emphasizing the positive adhesive effect of TSC on the bond strength between a high temperature fused ceramic material (PDT) and polymer based material (PMMA).

In groups without pin, SB/AE-P group showed the highest bond strength values $(47.6 \mathrm{~N}$ \pm 10.5 ) after those of TSC-P group. This finding indicates the effectiveness of sandblasting followed by acid etching in increasing the retentive strength between PDT and PMMA. The SB-P group demonstrated lower bond strength values $(18.1 \mathrm{~N} \pm 4.0)$ compared to TSC-P and SB/AE-P groups, indicating that sandblasting alone do not sufficiently improve the bond between PDT and PMMA. The low bond strength values obtained in the control group CON-P, emphasizes the necessity of using surface treatment methods when placing a PDT without retentive pin on a PMMA denture. Therefore, from a different point of view, it can be deduced that compared to the negative control group CON-P $(4.6 \mathrm{~N} \pm 5.4)$, the sandblasting procedure (SB-P) increased fourfold, the sandblasting and acid etching procedure (SB/AE-P) increased
Gelöscht: un Mutlu Özcan 25.10.11 20:14

Gelöscht: ) 
tenfold, and the tribochemical silica coating procedure increased twentyfold the bond strength between PDT and PMMA. The adhesive performance of TSC in PDT specimens without pins was almost similar to PDT specimens with pins.

The effect of woven fiber coating on PDT-PMMA bond strength was a fully unknown matter at the beginning of the study. The results obtained in group FB-P $(0.0 \mathrm{~N})$ showed that, compared to CON-P, fiber coating totally eliminates the retention between PDT and PMMA in PDT specimens without retentive pins, and significantly decreases $(77.7 \mathrm{~N} \pm 18.3)$ the retention in PDT specimens with pins, when compared with CON+P $(103.1 \mathrm{~N} \pm 39.6)$.

Comparable results were reported in the study of Marchack et al [11], who found that high energy air abrasion and hydrofluoric acid etching procedures combined with the use of a general purpose bonding agent improved the bond strength of heat-polymerized denture PMMA to porcelain denture teeth.

The failure modes supported these findings, Groups without pin (CON-P, SB-P, SB/AE$\mathrm{P}, \mathrm{FB}-\mathrm{P})$ did not display any cohesive fracture, except group TSC-P in which 3 specimens showed cohesive fracture in PMMA. This result emphasizes the strong bonding effect of tribochemical silica coating on high fusing ceramic surfaces (PDT). Groups SB/AE+P and TSC+P displayed totally 7 cohesive fractures in PDT bodies indicating the effectiveness of combining mechanical and adhesive bonding,

The repetition of described bond strength tests to display the attachment between PDT and PMMA after the application of various aging procedures or the effect of physicochemical surface treatment procedures on stain ingress between PDT and PMMA could be the topic of future studies.

Mutlu Özcan 25.10.11 20:15

Gelöscht: quite equal

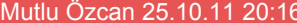

Gelöscht: Correlative

Mutlu Özcan 25.10.11 20:17

Gelöscht: Paralel correlative results were determined with the assessment of failure modes of test groups (Table 4)

Gelöscht: (Table 4) 


\section{CONCLUSIONS}

Within the limitations of the present study it was determined that;

1. The highest mean bond strength values between porcelain denture teeth (PDT) and acrylic resin denture base materials (PMMA) were obtained when mechanical (retentive pin) and adhesive retentive means (tribochemical silica coating followed by silanization) are combined.

2. Elimination of palatal retentive pins significantly decreases the bond strength between PMMA and PDT.

3. If the length reduction or elimination of a PDT's retentive pin is necessary due to clinical reasons such as jimited interocclusal distance or prominent metal framework, tribochemical silica coating of palatal PDT surfaces followed by silanization, provides the highest bond strength compared to sandblasting-acid etching combination, and sandblasting alone.

4. Fiber coverage on PDT surfaces significantly decreased, the PDT-PMMA bond in groups with pins, and eliminated, the bond in groups without pins. 


\section{REFERENCES}

[1]. Felton DA. Edentulism and comorbid factors. J Prosthodont 18, 88-96 (2009)

[2]. Beltran-Aguilar ED, Barker LK, Canto MT, et al. Surveillance for dental caries, dental sealants, tooth retention, edentulism, and enamel fluorosis-United States, 1988-1994 and 1999-2002. MMWR Surveill Summ 54, 1-43 (2005).

[3]. Douglas CW, Shih A, Ostry L. Will there be a need for complete dentures in the United States in 2020? J Prosthet Dent 87, 5-8 (2002).

[4]. Brown, L.R., Flavin, C., and French, H. A new economy for a new century. State of the world. (W.W. Norton \& Company) New York; pp:5-7 (1999).

[5]. Phillips, R.W. Science of dental materials. (WB Saunders Co) $9^{\text {th }}$ ed, p.516. (1991).

[6]. Zarb G.A., Bolender C.L., and Hickey J.C. Boucher's Prosthodontic Treatment for Edentulous Patients. $10^{\text {th }}$ Ed. Mosby Co. (1990).

[7]. Darbar U.R., Huggett, R., and Harrison, A. Denture fracture - a survey. Br Dent J. 176, 342-5 (1994).

[8]. Sumithra, N., Waknine, S., and S,chulman A. Bond strength of etched porcelain denture teeth of PMMA. Quintessence Int. 17, 745-8 (1986).

[9]. Paffenbarger, G.C., Sweeney, W.T., and Bowen, R.L. Bonding porcelain teeth to acrylic resin denture bases. J Am Dent Assoc. 74, 1068-73 (1967).

[10]. Moffa, J.P., Jenkins, W.A., and Weaver, R.G. Silane bonding of porcelain denture teeth to acrylic resin denture bases. J Prosthet Dent. 33, 620-7 (1975).

[11]. Marchack, B.W., Yu, Z., and Zhao, X.Y. Adhesion of denture tooth porcelain to heatpolymerized denture resin. J Prosthet Dent. 74, $242-9$ (1995).

[12]. Guggenberger, R. Rocatec system - adhesion by tribochemical coating. Dtsch Zahnarztl Z. 44, 874-6 (1989).

[13]. Özcan, M. A practical method for chairside repair of debonded porcelain denture teeth. $J$ Prosthodont. 15, 47-50 (2006).

[14]. Özcan, M., and Niedermejer, W. Clinical study on the reasons and location of the failures of metal-ceramic restorations and survival of repairs. Int J Prosthodont. 15, 299-302 (2002). 
[15]. Özcan, M. The use of chairside silica coating for different dental applications: a clinical report. J Prosthet Dent. 87, 469-72 (2002).

[16]. Özcan, M., and Akkaya, A. New approach to bonding all-ceramic adhesive fixed partial dentures: a clinical report. J Prosthet Dent. 88, 252 (2002). 


\section{TABLES}

Table 1. İdentification of experimental groups

\begin{tabular}{|l|c|c|}
\hline Groups $(n=10)$ & Retentive Pin & Surface Treatment \\
\hline CON $+P$ & $(+)$ & No treatment \\
\hline SB $+\mathrm{P}$ & $(+)$ & Sandblasting \\
\hline SB/AE+P & $(+)$ & Tribochemical silica coating \\
\hline TSC+P & $(+)$ & Fiber coating \\
\hline FB+P & $(+)$ & Sandbatasting \\
\hline CON-P & $(-)$ & Sandblasting and acid etching \\
\hline SB-P & $(-)$ & Tribochemical silica coating \\
\hline SB/AE-P & $(-)$ & Fiber coating \\
\hline TSC-P & $(-)$ & \\
\hline FB-P & $(-)$ & \\
\hline
\end{tabular}


Table 2. Mean, minimum, maximum, and standard deviation values of tested groups.

\begin{tabular}{|c|c|c|c|c|}
\hline Groups & Min. & Max. & Mean & St.Dev. \\
\hline CON-P & 0.0 & 14.5 & 4.6 & 5.4 \\
\hline SB-P & 12.2 & 24.5 & 18.1 & 4.0 \\
\hline SB/AE-P & 34.3 & 60.7 & 47.6 & 10.5 \\
\hline TSC-P & 60.6 & 137.1 & 90.6 & 22.2 \\
\hline FB-P & 0.0 & 0.0 & 0.0 & 0.0 \\
\hline CON+P & 36.0 & 168.1 & 103.1 & 39.6 \\
\hline SB+P & 52.7 & 189.5 & 113.5 & 47.3 \\
\hline SB/AE+P & 73.8 & 168.6 & 112.2 & 26.1 \\
\hline TSC+P & 81.2 & 165.8 & 132.5 & 26.5 \\
\hline FB+P & 49.6 & 107.1 & 77.7 & 18.3 \\
\hline & & & & \\
\hline
\end{tabular}


Table 3. Comparisons between experimental groups (Significance level; $p<.05$, *).

\begin{tabular}{|c|c|c|c|}
\hline Groups & $\mathrm{p}$ & Groups & $\mathrm{p}$ \\
\hline $\mathrm{CON}+\mathrm{P} / \mathrm{SB}+\mathrm{P}$ & 1 & SB/AE+P / FB-P & $0.024^{*}$ \\
\hline $\mathrm{CON}+\mathrm{P} / \mathrm{SB} / \mathrm{AE}+\mathrm{P}$ & 1 & $T S C+P / F B+P$ & $0.045^{*}$ \\
\hline $\mathrm{CON}+\mathrm{P} / \mathrm{TSC}+\mathrm{P}$ & 1 & TSC+P / CON-P & $0.005^{*}$ \\
\hline $\mathrm{CON}+\mathrm{P} / \mathrm{FB}+\mathrm{P}$ & 1 & TSC+P / SB-P & $0.007^{*}$ \\
\hline CON+P / CON-P & $0.005^{*}$ & TSC+P / SB/AE-P & $0.007^{*}$ \\
\hline $\mathrm{CON}+\mathrm{P} / \mathrm{SB}-\mathrm{P}$ & $0.007^{*}$ & TSC+P / TSC-P & 0.09 \\
\hline $\mathrm{CON}+\mathrm{P} / \mathrm{SB} / \mathrm{AE}-\mathrm{P}$ & 0.18 & TSC+P / FB-P & $0.024^{*}$ \\
\hline $\mathrm{CON}+\mathrm{P} / \mathrm{TSC}-\mathrm{P}$ & 1 & $\mathrm{FB}+\mathrm{P} / \mathrm{CON}-\mathrm{P}$ & $0.005^{*}$ \\
\hline $\mathrm{CON}+\mathrm{P} / \mathrm{FB}-\mathrm{P}$ & $0.024^{*}$ & $F B+P / S B-P$ & $0.007^{*}$ \\
\hline $\mathrm{SB}+\mathrm{P} / \mathrm{SB} / \mathrm{AE}+\mathrm{P}$ & 1 & $\mathrm{FB}+\mathrm{P} / \mathrm{SB} / \mathrm{AE}-\mathrm{P}$ & $0.045^{\star}$ \\
\hline $\mathrm{SB}+\mathrm{P} / \mathrm{TSC}+\mathrm{P}$ & 1 & $\mathrm{FB}+\mathrm{P} / \mathrm{TSC}-\mathrm{P}$ & 1 \\
\hline $\mathrm{SB}+\mathrm{P} / \mathrm{FB}+\mathrm{P}$ & 1 & $F B+P / F B-P$ & $0.024^{*}$ \\
\hline $\mathrm{SB}+\mathrm{P} / \mathrm{CON}-\mathrm{P}$ & $0.005^{*}$ & CON-P / SB-P & $0.001^{*}$ \\
\hline SB+P / SB-P & $0.007^{*}$ & CON-P / SB/AE-P & $0.005^{*}$ \\
\hline $\mathrm{SB}+\mathrm{P} / \mathrm{SB} / \mathrm{AE}-\mathrm{P}$ & $0.045^{*}$ & CON-P / TSC-P & $0.005^{*}$ \\
\hline SB+P / TSC-P & 1 & CON-P / FB-P & 1.395 \\
\hline$S B+P / F B-P$ & $0.024^{*}$ & SB-P / SB/AE-P & $0.007^{*}$ \\
\hline $\mathrm{SB} / \mathrm{AE}+\mathrm{P} / \mathrm{TSC}+\mathrm{P}$ & 1 & SB-P / TSC-P & $0.007^{*}$ \\
\hline $\mathrm{SB} / \mathrm{AE}+\mathrm{P} / \mathrm{FB}+\mathrm{P}$ & 0.18 & SB-P / FB-P & $0.024^{*}$ \\
\hline SB/AE+P / CON-P & $0.005^{*}$ & SB/AE-P / TSC-P & $0.009^{*}$ \\
\hline SB/AE+P / SB-P & $0.007^{*}$ & SB/AE-P / FB-P & $0.024^{*}$ \\
\hline SB/AE+P / SB/AE-P & $0.007^{*}$ & TSC-P/FB-P & $0.024^{*}$ \\
\hline SB/AE+P / TSC-P & 1 & & \\
\hline
\end{tabular}


Table 4. Failure modes of tested groups

\begin{tabular}{|c|c|c|c|c|}
\hline Groups & Cohesive in PMMA & Cohesive in PDT & Adhesive & $\begin{array}{c}\text { Adhesive and } \\
\text { PMMA-PDT }\end{array}$ \\
Cohesive \\
\hline SB-P & 0 & 0 & 10 & 0 \\
\hline SB/AE-P & 0 & 0 & 10 & 0 \\
\hline TSC-P & 3 & 0 & 9 & 1 \\
\hline FB-P & 0 & 0 & 3 & 4 \\
\hline CON+P & 10 & 0 & 10 & 0 \\
\hline SB+P & 3 & 1 & 0 & 0 \\
\hline SB/AE-P & 0 & 4 & 1 & 5 \\
\hline TSC+P & 0 & 3 & 1 & 6 \\
\hline FB+P & 2 & 0 & 54 & 20 \\
\hline TOTAL & 18 & 8 & & 3 \\
\hline
\end{tabular}


FIGURES

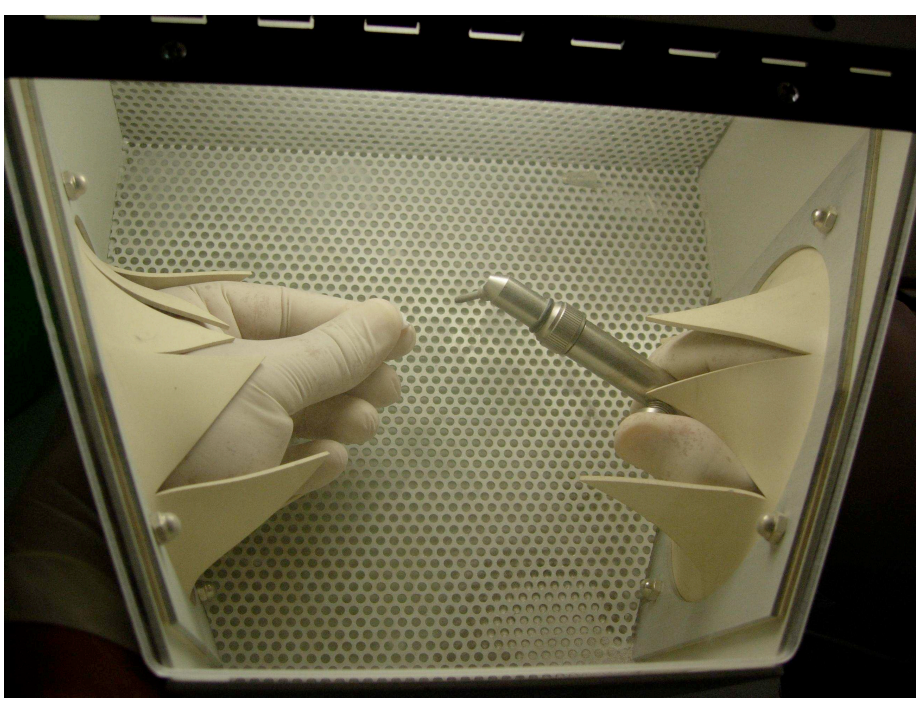

Figure 1. Particle abrasion of PDT specimens in a closed chamber 


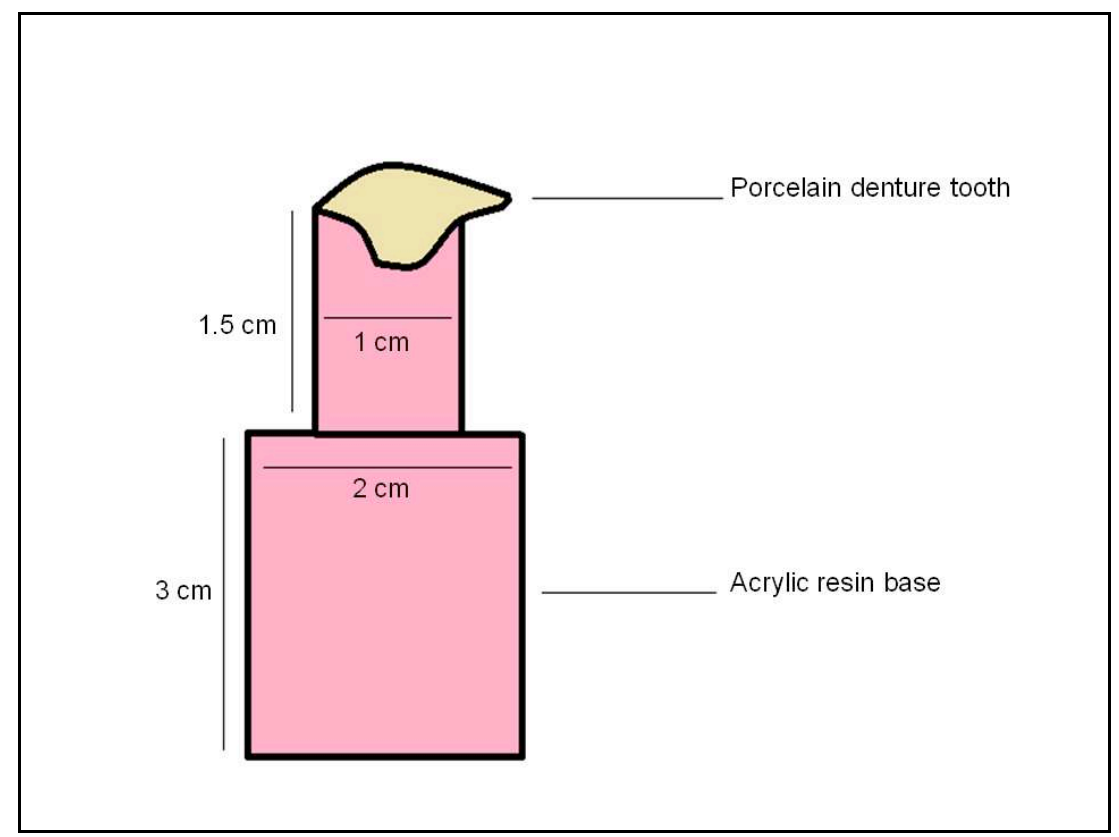

Figure 2. Schematic description and dimensions of tested specimens 


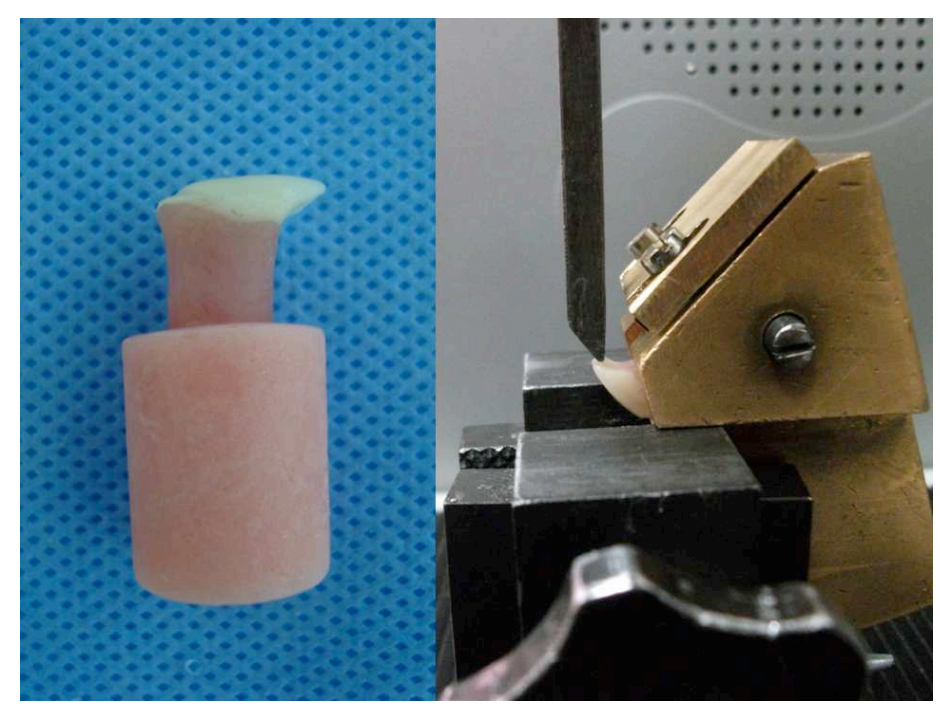

Figure 3a. Porcelain denture tooth specimen with the acrylic resin cylinder on $2 / 3$ palatal surface. 3b. PDT specimen clamped by its acrylic projection on testing machine with a 45degree angle to the horizontal plane, and loading bar positioned perpendiculary to the horizontal plane to contact the center of the inclined palatoincisal surfaces. 


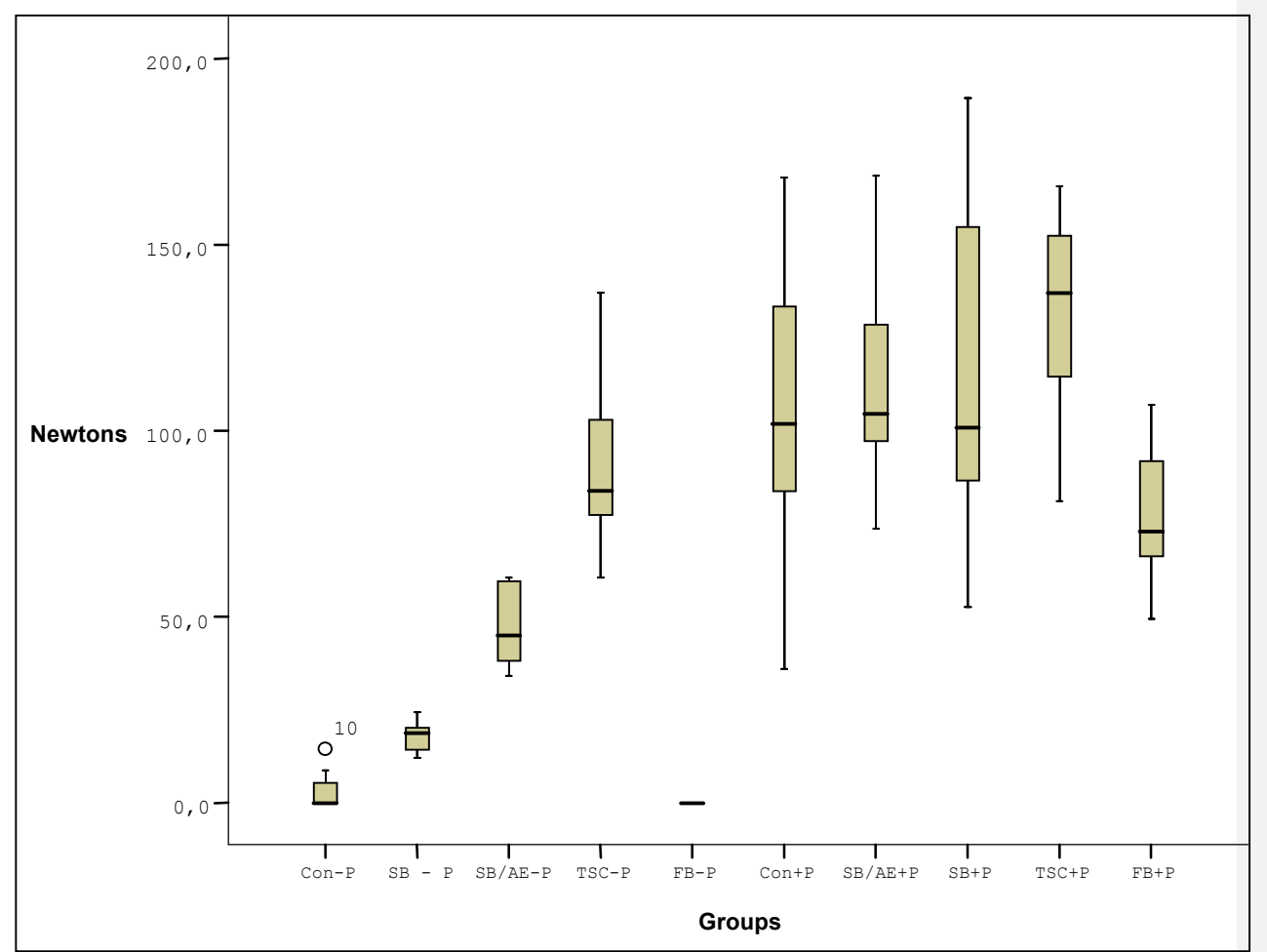

Figure 4. Boxplot of mean force $(\mathrm{N})$ values of experimental groups 